Available online at https://jurnal.stmikroyal.ac.id/index.php/jurdimas

\title{
PEDAMPINGAN PENGGUNAAN SISTEM INFORMASI PROFIL DESA BANYUASIN BERBASIS INTERNET DAN APLIKASI MOBILE
}

\author{
Ghiri Basuki Putra ${ }^{1^{*}}$, Eddy Jajang Jaya Atmaja ${ }^{2}$ \\ ${ }^{1}$ Jurusan Teknik Elektro, Fakultas Teknik, Universitas Bangka Belitung \\ ${ }^{2}$ Jurusan Agribisnis, Fakultas Pertanian Perikanan dan Biologi, Universitas Bangka Belitung \\ email: *ghiri_basuki@ubb.ac.id
}

\begin{abstract}
The development of information and communication technology is currently growing rapidly and has touched almost all levels of society. With the advancement of information technology, the dissemination of information is accelerating and is not limited to space and time. The village is currently getting special attention from the government with the large budget given to each village to advance rural villages in Indonesia. However, these funds are still very minimal for development in the field of information technology. In fact, every village needs information technology, especially information systems to help the performance of the village government in providing services to the community and to facilitate data and information management. This information system will provide complete information and facilitate the dissemination of information in the digital era by utilizing the Internet. Banyuasin Village does not yet have a village information system in managing data and information and for conveying information to the community. This service method is community education by conducting discussions, interviews, socialization and training for the system that has been built so that it can be used by the village of Banyuasin. The village information system that was built provided benefits in the field of information technology and made Banyuasin Village a mobile application-based Information and Communication Technology-based village.
\end{abstract}

Keywords: information system; village profile; website

\begin{abstract}
Abstrak: Perkembangan teknologi informasi dan komunikasi saat ini semakin pesat dan telah menyentuh hampir ke seluruh lapisan masyarakat. Dengan kemajuan teknologi informasi menyebabkan penyebarluasan informasi semakin cepat dan tidak terbatas dengan ruang dan waktu. Desa saat ini mendapatkan perhatian khusus dari pemerintah dengan besarnya anggaran yang diberikan ke tiap desa untuk memajukan desa desa di Indonesia. Hanya saja, dana tersebut masih sangat minim untuk pengembangan di bidang teknologi Informasi. Padahal setiap desa membutuhkan teknologi informasi terutama sistem informasi untuk membantu kinerja pemerintah desa dalam memberikan layanan kepada masyarakat serta memudahkan dalam pengelolaan data dan informasi. Sistem informasi ini akan memberikan informasi lengkap dan dan memudahkan penyebarluasan informasi pada era digital dengan pemanfaatan Internet. Desa Banyuasin belum mempunyai sistem informasi desa dalam pengelolaan data dan informasi serta untuk menyampaikan informasi ke masyarakat. Metode pengabdian ini adalah pendidikan masyarakat dengan melakukan diskusi, wawancara, sosialisasi dan pelatihan untuk sistem yang telah dibangun agar dapat digunakan oleh desa Banyuasin. Sistem informasi desa yang di bangun memberikan manfaat di bidang teknologi informasi dan membuat Desa Banyuasin menjadi desa yang berbasis Teknologi Informasi dan Komunikasi berbasis aplikasi mobile.
\end{abstract}

Kata kunci : profil desa; sistem informasi; website 
Available online at https://jurnal.stmikroyal.ac.id/index.php/jurdimas

\section{PENDAHULUAN}

Pemanfaatan teknologi informasi dan internet telah menjadi hal yang wajib untuk dilakukan oleh pemerintah dalam memberikan layanan yang berkualitas kepada masyarakat. Dengan teknologi informasi dapat meningkatkan daya saing serta kinerja pemerintahan dalam hal menyebarluaskan informasi serta mempermudah kinerja administrasi ketika memberikan pelayanan.

Internet merupakan salah satu dari kecanggihan teknologi informasi dan komunikasi. Dengan menggunakan internet memungkinkan individu memperoleh informasi apapun yang ada dan bertukar informasi tanpa terhambat oleh batas ruang dan waktu (Bariyyah \& Permatasari, 2017). Dengan adanya internet segala informasi dan perkembangan di dunia lebih mudah diakses dan diketahui (Windarto, Hartama, Wanto \& Parlina, 2018).

Teknologi informasi telah memberikan banyak kemudahan terutama manfaat untuk meningkatkan produktivitas suatu instansi pemerintahan. Salah satu teknologi informasi yang memudahkan kinerja adalah sistem informasi yang merupakan sebuah sistem untuk melakukan pengelolaan, penyimpanan dan pengiriman data dan informasi.

Sistem Informasi adalah kombinasi dari manusia, fasilitas atau alat teknologi, media, prosedur dan pengendalian yang bermaksud menata jaringan komunikasi yang penting, proses atas transaksi-transaksi tertentu dan rutin, membantu manajemen dan pemakai internet dan menyediakan dasar pengambilan keputusan yang tepat (Pasaribu \& Musa, 2012). Berdasarkan pengertian tersebut, sistem informasi didefinisikan sebagai perangkat lunak yang membantu mengatur dan menganalisa data.

Jadi, tujuan sistem informasi adalah mengubah data mentah menjadi informasi bermanfaat yang dapat digunakan untuk pengambilan keputusan dalam suatu organisasi. selain itu, merupakam seperangkat komponen terpadu untuk mengumpulkan, menyimpan, dan memproses data dan untuk menyediakan informasi, pengetahuan, dan produk digital (Avenzora \& Teguh, 2013). Dengan penggunaan sistem informasi yang baik maka pemerintah desa dapat memberikan layanan kepada masyarakat dengan baik dalam rangka menerapkan sistem Good Governance pada pemerintahan daerah dan desa.

Salah satu manfaat sistem informasi desa adalah untuk memberikan kemudahan bagi para stakeholder dalam memperoleh dan mengelola informasi yang diperlukan pada desa yang dituju (Janianton \& Weber, 2006). Masyarakat juga diberikan kemudahan dalam proses pemberian layanan serta mendapatkan akses informasi yang dibutuhkan.

Serta diharapkan dengan sistem informasi desa ini dapat mengundang investor untuk menanamkan modal dalam mengembangkan desa di masa depan. Desa Banyuasin merupakan salah satu desa yang ada di Kabupaten Bangka, Provinsi Kepulauan Bangka Belitung yang sampai saat ini belum memiliki sistem informasi desa serta profil desa lengkap.

Pelayanan di desa Banyuasin masih secara manual belum ke arah digitalisasi, paperless serta online, sehingga sangat diperlukan sistem informasi desa untuk meningkatkan kualitas informasi serta peningkatan 
Available online at https://jurnal.stmikroyal.ac.id/index.php/jurdimas

daya saing desa dimasa depan terutama di bidang teknologi informasi. Dengan adanya Sistem informasi Desa Banyuasin, diharapkan dapat memberikan akses kepada para masyarakat desa dan luas untuk mendapatkan informasi lengkap tentang Desa Banyuasin.

Kekurangan yang ada di desa Banyuasin dijabarkan sebagai berikut:

1. Belum adanya system informasi desa dalam pengelolaan informasi dan untuk memberikan layanan ke masyarakat desa.

2. Profil desa masih belum lengkap dan harus bisa memberikan informasi lengkap kepada masyarakat baik masyarakat desa Banyuasin sendiri maupun masyarakat luas;

3. Pegelolaan informasi masih sangat minim serta pelatihan di bidang Teknologi Informasi masih kurang;

4. Perlunya ada SDM di bidang TI yang bisa dalam mengembangan dan memanfaatkan teknologi informasi di Desa;

Dari permasalahan tersebut, ada sebuah solusi berupa sebuah sistem informasi dan profil desa berbasis internet dan aplikasi mobile yang dapat memberikan informasi dan potensi Desa Banyuasin melalui jaringan Internet sehingga bisa diakses secara luas.

Sistem informasi ini memberikan kemudahan bagi desa Banyuasin dalam pengelolaan informasi dan memberikan informasi serta untuk meningkatkan pelayanan kepada masyarakat.

\section{METODE}

Metode yang digunakan pada pembuatan sistem informasi Desa
Banyuasin adalah pendidikan masyarakat, adapun tahapan yang dilakukan diantaranya:

1. Analisa Kebutuhan untuk system informasi

2. Wawancara dan pengumpulan data

3. Pembuatan Sistem Informasi desa

4. Mempersiapkan rancangan sistem informasi atau database yang akan digunakan;

5. Merancang desain sistem informasi yang responsif dan menarik;

6. Mengumpulkan data;

7. Verifikasi data;

8. Sosialisasi system informasi

9. Pelatihan kepada Aparatur Desa di untuk pengelolaan sistem informasi

Data yang dikumpulkan oleh tim pengabdi dapat berasal dari perangkat desa yang bersangkutan dan dapat juga berupa data hasil observasi lapangan yang dilengkapi dengan dokumentasi dan video pendek.

Website yang dibangun dilengkapi dengan informasi yang lengkap tentang desa Banyuasin terutama potensi Agro Wisata, sehingga informasi yang disampaikan mengenai potensi desa Banyuasin dapat tersampaikan kepada masyarakat luar.

Setelah website dibangun dan telah bisa diakses, langkah lanjut kedepannya adalah memantau perkembangan website tersebut dan selalu memberikan pembinaan terhadap operator website tersebut agar website Desa Banyuasin dapat terus memberikan informasi yang terbaru dan menarik.

Adanya beberapa permasalahan yang dihadapi oleh staf desa Banyuasin tersebut adalah sebagai berikut:

1. Kurangnya kemampuan staf dalam penggunaan dan pengembangan system informasi di desa untuk melayani masyarakat 
Available online at https://jurnal.stmikroyal.ac.id/index.php/jurdimas

2. Kurangnya kemampuan staff dalam menyusun laporan keuangan/ pertanggungjawaban

\section{PEMBAHASAN}

Pada bagian ini menjelaskan bagaimana tampilan website serta penjelasan bagaimana proses pelatihan kepada para staff desa Banyuasin.

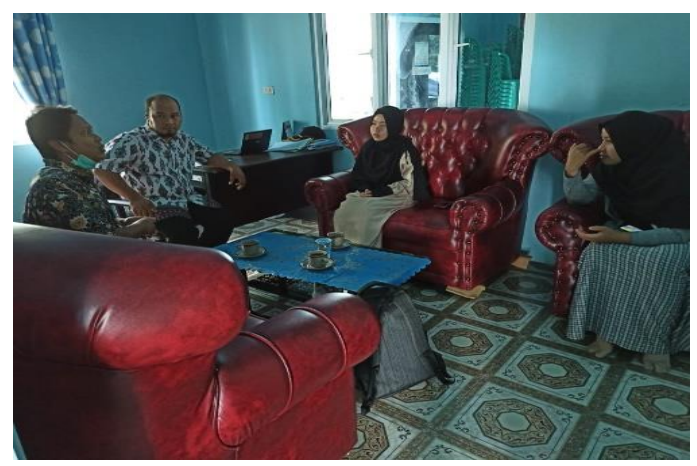

\section{Gambar 1. Proses Diskusi dengan Desa Banyuasin}

Pada Gambar 1, merupakan proses diskusi untuk pembuatan desa dan permintaan data data yang dibutuhkan dalam pembuatan bagi website profil desa nanti, sehingga website yang dibangun lebih lengkap dan lebih memudahkan dalam pengelolaan informasi. Website yang dibangun memberikan tampilan menarik dan informasi yang lengkap agar menarik bagi masyarakat dan memberikan layanan yang lengkap bagi masyarakat baik Desa Banyuasin maupun diluar desa Banyuasin.

Pada Gambar 2 merupakan halaman utama dari website yang akan memberikan menu menu tentang Desa Banyuasin yang memudahkan dalam masyarakat mendapatkan informasi lengkap tentang Desa. Pada Gambar 3 merupakan beberapa contoh destinasi wisata yang ada di Desa Banyuasin untuk dikunjungi dan dapat menarik wisatawan datang berkunjung.

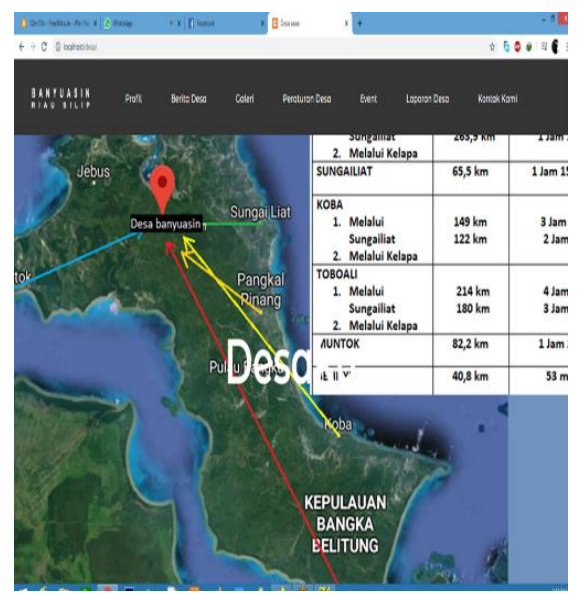

\section{Gambar 2. Tampilan UtamaWebsite Desa}

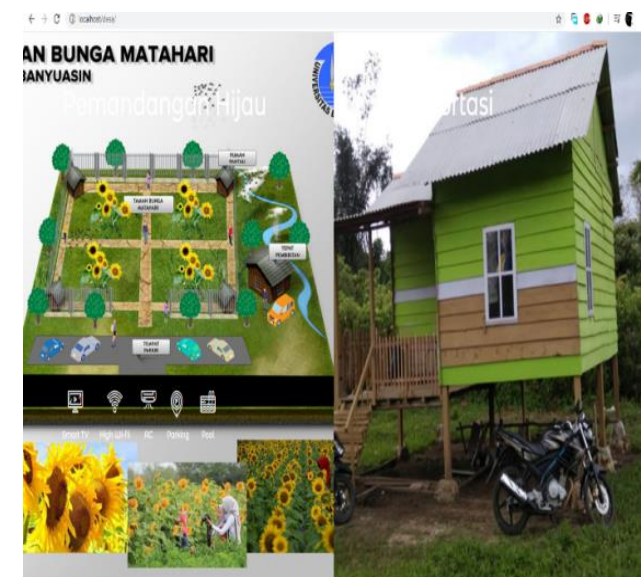

Gambar 3. Tampilan Tujuan Wisata Desa Banyuasin

Pada kegiatan pengabdian ini, juga memberikan pelatihan dan sosialisasi tentang system yang telah dibangun agar dapat digunakan dan dimanfaatkan untuk kepentingan desa Banyuasin dalam peningkatan pelayanan kepada masyarakat desa.

Dengan pelatihan kepada staf diharapkan akan meningkatkan kemampuan staf dalam penggunaan system dan kemampuan di bidang teknologi informasi serta melakukan sosialisasi kepada masyarakat desa agar 
Available online at https://jurnal.stmikroyal.ac.id/index.php/jurdimas

mengetahui layanan desa dengan menggunakan system informasi ini.

Selesai pelatihan dan sosialisasi maka akan terus dilakukan pendampingan dan pengembangan sistem yang telah dibangun agar dapat terus berjalan dan digunakan oleh desa Banyuasin serta melakukan perbaikan dan pengembangan sistem apabila diperlukan dan diminta oleh pihak desa.

\section{SIMPULAN}

Sistem informasi dan profil desa ini diharapkan dapat memberikan nilai tambah bagi desa Banyuasin dan meningkatkan pemanfaatan Teknologi Informasi dalam pelayanan kepada masyarat serta memberikan informasi yang lengkap dan menarik tentang desa Banyuasin sebagai desa Agro wisata. Hal ini memberikan keuntungan dan meningkatkan kunjungan wisatawan ke desa Banyuasin yang membuat perekonomian desa banyuasin juga akan meningkat.

Tujuan pengabdian ini tercapai Untuk peningkatan Kompetensi staf desa dalam penggunaan sistem informasi adalah Staf desa bisa menggunakan system informasi desa untuk melayani masyarakat dan untuk peningkatan pelayanan kepada masyarakat berbasis sistem informasi

\section{UCAPAN TERIMA KASIH}

Ucapkan terima kasih disampaikan kepada Lembaga Penelitian dan Pengabdian Masyarakat UBB yang telah mendanai pengabdian melalui skema Pengabdian Masyarakat Tingkat universitas 2020 untuk melakukan pengabdian di Desa Banyuasin,
Kecamatan Riau Silip Kabupaten Bangka.

\section{DAFTAR PUSTAKA}

Avenzora, R., \& Teguh, F. (2013). Ekowisata dan Pengembangan Pariwisata Berkelanjutan di Indonesia: Potensi, Pembelajaran, dan Kesuksesan.

Bariyyah, K., \& Permatasari, D. (2017). Pelatihan Pemanfaatan Media Online Dalam Layanan Bimbingan Konseljng Bagi Konselor Sekolah Menengah Pertama Di Kabupaten Pamekasan Madura. Dedication: Jurnal Pengabdian Masyarakat, 1(1), 63-69.

Efendi, Z. (2020). APPLICATION OF THE SMART METHOD TO DETERMINE THE BEST VILLAGE. Proceeding International Conference on Social, Sciences and Information Technology (ICoSSIT). https://doi.org/doi.org/10.33330 /icossit.v1i1.713

Janianton, D., \& Weber, H. F. (2006). Perencanaan Ekowisata Dari Teori Ke Aplikasi. Yogyakarta: Andi Offset , 2006. https://opac.perpusnas.go.id/Det ailOpac.aspx ?id=541840

Pasaribu, \& Musa, A. (2012). Perencanaan \& Evaluasi Proyek Agribisnis (Konsep \& Aplikasi). ANDI : JOGYAKARTA., 2012. http://repo.unikadelasalle.ac.id/i ndex.php?p=show_detail\&id=6 539\&keywords=

Windarto, A. P., Hartama, D., Wanto, A., \& Parlina, I. (2018). 
Jurdimas (Jurnal Pengabdian Kepada Masyarakat) Royal

Vol. 4 No. 1, Januari 2021, hlm. 97 - 102

DOI: https://doi.org/10.33330/jurdimas.v4i1.897

ISSN 2622-3813 (Online)

Available online at https://jurnal.stmikroyal.ac.id/index.php/jurdimas

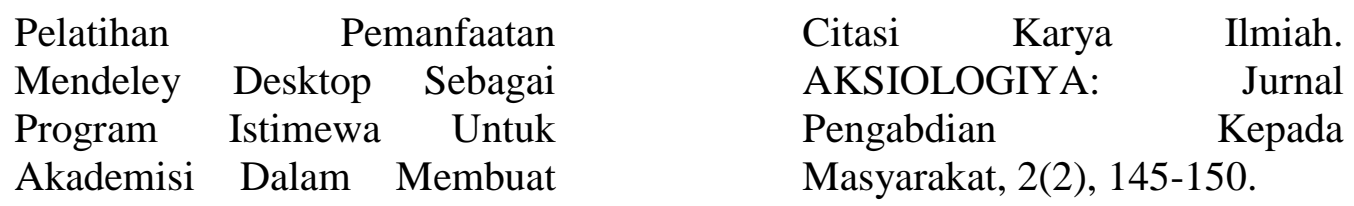

